\title{
A Study on Antimicrobial Properties and Medicinal Value of Adhatoda vasica, Centella asiatica, Paederia foetida, Nyctanthes arbor-tristis, Ocimum tenuiflorum
}

\section{Anju Paul ${ }^{1^{*}}$, Amit Kumar Barman ${ }^{2}$, Pradip Kumar Roy ${ }^{2}$ and Subhajit Ray ${ }^{3}$}

${ }^{1}$ Department of Food Technology, Guru Nanak Institute of Technology, India

${ }^{2}$ Faculty of Dairy Technology, WBUAFS, Mohanpur Campus, W.B., Nadia-741252, India

${ }^{3}$ Department of Food Engineering and Technology, CIT, Assam-783370, India

*Corresponding author

\section{A B S T R A C T}

\section{Keywords}

Medicinal plants,

Pharmacological activity, herbs, polyphenols

\section{Article Info}

Accepted:

12 April 2018

Available Online:

10 May 2018
The use of various herbal remedies and preparations are described throughout human history representing the origin of modern medicine. Herbal medicine is also called botanical medicine or phyto-medicine, and is defined as the use whole plants or part of plants to prevent or treat illness. Medicinal plants constitute an important component of flora and are widely distributed in India. The pharmacological evaluation of substances from plants is an established method for the identification of lead compounds which can leads to the development of novel and safe medicinal agents. The importance of medicinal plants and traditional health systems in solving the health care problems of the world is gaining increasing attention. Because of this resurgence of interest, the research on plants of medicinal importance is growing phenomenally at the international level, often to the detriment of natural habitats and mother populations in the countries of origin. The study on antimicrobial and medicinal values of: Adhatoda vasica (vasaka), Centella asiatica (thankuni), Paederia foetida (gadal), Nyctanthes arbor-tristis (shiuli), will help us to understand their anti-microbial property so that they can be used in more effective and efficient manner for pharmacological purposes.

\section{Introduction}

World Health Organisation (WHO) has defined medicinal plants as plants that contain properties or compounds that can be used for therapeutic purposes or those that synthesize metabolites to produce useful drugs. Medicinal plants constitute an important component of flora and are widely distributed in India. The pharmacological evaluation of substances from plants is an established method for the identification of lead compounds which can leads to the development of novel and safe medicinal agents. The importance of medicinal plants and traditional health systems in solving the health care problems of the world is gaining increasing attention. Because of this resurgence of interest, the research on plants of medicinal importance is growing phenomenally at the international level, often to the detriment of natural habitats and mother 
populations in the countries of origin. Most of the developing countries have adopted traditional medical practice as an integral part of their culture (Chopra et al., 1992; Ghani 2003). Historically, all medicinal preparations were derived from plants, whether in the simple form of raw plant materials or in the refined form of crude extracts, mixtures, etc. Recent estimates suggest that several thousands of plants have been known with medicinal applications in various cultures.

A large proportion of such medicinal compounds have been discovered with the aid of ethno-botanical knowledge of their traditional uses. The rich knowledge base of countries like India and China in medicinal plants and health care has led to the keen interest by pharmaceutical companies to use this knowledge as a resource for research and development programs in the pursuit of discovering novel drugs. India is a varietal emporium of medicinal plants and it is one of the richest countries in the world as regards genetic resources of medicinal plants. It exhibits a wide range in topography and climate, which has a bearing on its vegetation and floristic composition. More over the agro climatically conditions are conducive for introducing and domesticating new exotic plant varieties. At present majority of the people are relying for their primary health care on traditional medicine. In this project report we will discuss about the medicinal values and study report of anti-microbial characteristics of: Adhatoda vasica, Centella asiatica, Nyctanthes arbor-tristis, Paederia foetida

All these four herbs have significant effect on human health:

Adhatoda vasica leaves contain carotene, vitamin $\mathrm{C}$, essential oils and the whole plant in general acts as sedative, expectorant, antispasmodic, antiseptic, expectorant and anthelmintic, and also has compounds including crystalline, oroxylin, alkaloids vasicine, adhatodic acid and pectin. The roots, leaves, flowers and fruits are mainly used in treating bronchitis, cold, whooping cough and asthma. The whole plant is useful in the removal of intestinal parasites. Adhatoda vasica according Ayurveda, flowers are used for treating tuberculosis. Adhatoda vasica poultice from the leaves is applied for healing wounds, rheumatic pains and edema, whereas a warm decoction of the leaves is useful in treating scabies and other skin diseases. In acute stages of bronchitis, Adhatoda vasica gives is respected for unfailing, especially where When the dried leaves are smoked, they relieve asthma.

Centella asiatica is one of the main herbs for revitalizing the nerves and brain cells. Eastern healers relied on Centella asiatica to treat emotional disorders, such as depression, that were thought to be rooted in physical problems. In the Western medicine, during the middle of the twentieth century, Centella asiatica and its alcohol extracts reported to have shown positive results in the treatment of leprosy. The primary active constituents of Centella asiatica are saponins (also called triterpenoids), which include asiaticosides, in which a trisaccharide moiety is linked to the aglycone asiatic acid, madecassoside and madasiatic acid. These triterpene saponins and their sapogenins are mainly responsible for the wound healing and vascular effects by inhibiting the production of collagen at the wound site. Other components isolated from Centella asiatica, such as brahmoside and brahminoside, may be responsible for CNS and uterorelaxant actions, but are yet to be confirmed by clinical studies. Crude extract containing glycosides isothankuniside and thankuniside showed antifertility action in mice. Centelloside and its derivatives are found to be effective in the treatment of venous hypertension. In addition, the total extract contains plant sterols, flavonoids, and 
other components with no known pharmacological activity, namely, abundant tannins (20-25\%) (Tan et al., 2011), essential acid $(0.1 \%$ with beta-caryophyllene, transbeta-farnesene and germacrene D), phytosterols (campesterol, sitosterol, stigmasterol), mucilages, resins, free aminoacids (alanine, serine, aminobutyrate, aspartate, glutamate, lysine and threonine), flavonoids (derivatives of quercetin and kaempferol), an alkaloid (hydrochotine), a bitter component (vallerine), fatty acids (linoleic acids, linolenic, oleic, palmitic and stearic acids).

Paederia foetida (gandal) is a herb that has traditionally been used for a variety of purposes that seem to be centered around either intestinal health (particularly antidiarrheal and anti-dysentry) and as an invigorator for male health. Paederia foetida is known for the strong, sulphurous odour exuded when its leaves or stems are crushed or bruised. This is because the oil responsible for the smell, and found primarily within the leaves, contains sulphur compounds, including largely dimethyl disulphide. Paederia foetida contains an essential oil with offensive odour, two alkaloids "Alpa-paederine and Betapaederine." The plant gives off an offensive odour of sulfur compounds. Fruit blackens the teeth and is a specific agent against toothache. Leaves and roots are wholesome and tonic, and are used as an active constituent of a food given to a sick person. Leaves are boiled and made into soup which is also a good remedy for diarrhoea and dysentery and in convalescence from acute illness. The offensive odour is removed by the process of cooking. Juice of leaves is considered astringent and given to children in diarrhoea. Root is an emetic, and is also described as emollient and carminative, useful in colic pain, spasms, rheumatism and gout. Entire plant including stems, root and leaves, can be used both internally as well as externally in rheumatic affections.

Nyctanthes arbor-tristis (shiuli) is known as Parijat in India. Every part of this plant is used as medicinal plant to cure different diseases. The most common use of this plant is as an antihelminthic, cholagogoue and laxative. The claimed traditional medicinal uses have been proved on scientific basis using in vitro and in vivo experiments. The plant have been screened for antihistaminic activity, tranquillizing, anesthetic, analgesic, antiinflammatory, antipyretic, antiulcer, amoebicidal, anti-depressant, anti-viral and Immuno modulatory activities. Nyctanthes arbor-tristis is antibacterial, antiinflammatory, anthelmintic, expectorant, tonic, febrifuge and a mild purgative. The flowers are bitter astringent, ophthalmic, stomachic and carminative. Nyctanthes arbortristis is very useful in treating constipation in children. The leaves are used in Ayurvedic medicine, to treat sciatica, arthritis, fevers, rheumatism and various painful conditions. It has antioxidant properties (Parab et al., 2013). Its leaves are also made into a paste and used in skin related troubles, especially ringworm. The fresh leaves are boiled in mustard oil and used externally for treating ringworm. The leaf juice is mixed with common salt to treat intestinal worms. Nyctanthes arbor-tristis is used in the treatment of fungal skin infection, dry cough, and bronchitis and as an antidote for snakebites. The seeds are crushed and the aqueous paste is applied externally on the piles. They are also useful in treating baldness, scurvy and afflictions of the scalp. The decoction of night jasmine flower is used in treating gout. Patients with gynecological problems are advised to take 3 fresh night jasmine leaves, with 5 black peppers. The decoction of its seeds is used as a hair tonic. Washing hair daily with this tonic helps to get rid of dandruff and lice. Nyctanthes arbortristis is also used to treat anxiety, restlessness, headaches, gastritis, hepatitis, 
diarrhea, vertigo and dysmenorrhea.

Ocimum tenuiflorum, also known as Ocimum sanctum, Holy basil, or tulsī, is an aromatic plant in the family Lamiaceae. Some of the main chemical constituents of tulsi are oleanolic acid, ursolic acid, eugenol, carvacrol, linalool, $\beta$-caryophyllene, $\beta$ elemene and germacrene D.

A variety of studies and animal studies have indicated some potential pharmacological properties of Ocimum tenuiflorum or its extracts. Studies suggest tulsi may be painkillers, due to its high concentration of eugenol. Isolated $O$. sanctum extracts have some antibacterial activity against E. coli, S.aureus and $P$. aeruginosa. The Holy basil is also a herbal remedy for a lot of common ailments

\section{Materials and Methods}

Selection of medicinal plant: In the present work, herbs used were screened for potential antibacterial activity. Plant materials Leaves and stem were collected from different parts of Kolkata region.

\section{Determination of moisture content}

This method relies on measuring the mass of water in a known mass of sample. The moisture content is determined by measuring the mass of food before and after the water is removed by evaporation.

$\%$ moisture $=\left(\left(\mathrm{M}_{\text {initial }}-\mathrm{M}_{\text {dried }}\right) / \mathrm{M}_{\text {initial }}\right) \times 100$

Here, $\mathbf{M}_{\text {initial }}$ and $\mathbf{M}_{\text {dried }}$ are the mass of the sample before and after drying, respectively. The basic principle of this technique is that water has a lower boiling points than the other major component within foods e.g. lipids, proteins, carbohydrate and minerals.

\section{Determination of ash content}

Ash is an organic residue remaining after the waste and organic matter have been removed by heating in the presence of oxidising agents, which provides a measure of the total amount of minerals within a food. Analytical techniques for providing information about the total mineral are based on the fact that the minerals can be distinguish from all the other components within a food in measureable way. The most widely used methods are based on the fact that minerals are not destroyed by heating and they are a low volatility compared to other food components.

\section{Determination of total phenolic content}

The amount of total phenolics in extracts was determined with the Folin- Ciocalteu reagent. Gallic acid was used as a standard and the total phenolics were expressed as $\mathrm{mg} / \mathrm{g}$ gallic acid equivalents (GAE).The Folin-Ciocalteu reagent is sensitive to reducing compounds including polyphenols, thereby producing a blue colour upon reaction. This blue colour is measured spectrophotometrically.

\section{Determination of antimicrobial activity using standard plate count method}

The extracts from the leaves and stems of Adhatoda vasica, Centella asiatica, Paederia foetida, Ocimum tenuiflorum were evaluated for their antimicrobial activity using standard plate count method. The extracts in the 5\% concentration were tested against some pathogenic organisms like - E coli, B. subtilis, Klebsiella pneumoniae and Staphylococcus aureus.

The extracts exhibited antibacterial activity against tested organisms. The results obtained indicated that the leaves of the plant could be a potential source of treatment of disease against test 


\section{Moisture content}

First the weight of petridish is taken.

$3 \mathrm{~g}$ of sample is taken and kept in petridish.

Then the petridish was kept in the hot air oven at $105^{\circ} \mathrm{C}$.

After sometime the petridish is taken out from the hot air oven and weighed. This process is continued until the weight became constant. Finally, the moisture content is measured.

\section{Ash content}

At first weight of the crucible is taken.

Then $3 \mathrm{~g}$ of sample is taken and kept in crucible

Then it is kept in muffle furnace for 5 hours at $550^{\circ} \mathrm{C}$.

Then it is taken out and weighed.

\section{Phenolic content}

$5 \mathrm{~g}$ of sample is soaked in $25 \mathrm{ml}$ methanol and left overnight.

Then at different concentration sample is prepared.

Absorbance is observed in spectrophotometer at $760 \mathrm{~nm}$.

Total phenolic content is calculated in terms of GAE (Gallic acid equivalent).

\section{Antimicrobial activity}

Preparation of nutrient agar: $28 \mathrm{~g}$ Nutrient agar was mixed with $1000 \mathrm{ml}$ of Distilled water and placed in water bath till agar gets dissolved completely.
Glass goods (i.e. petridish, test tubes, and pipette) and nutrient agar were autoclaved at 15 psig for 15 minutes. Preparation of 5\% Herbal Extract: $5 \mathrm{ml}$ Herbal extract was diluted with $100 \mathrm{ml}$ of distilled water.

Serial dilution: 2 scoop full of strain were mixed properly in sterilised distilled water, from that $1 \mathrm{ml}$ is pipetted out and was poured onto another test tube containing $9 \mathrm{ml}$ sterilised distilled water. This method is continued till $10^{4}$ dilutions.

$0.1 \mathrm{ml}$ of $5 \%$ herbal extract, $0.1 \mathrm{ml}$ of $10^{4}$ dilution liquid containing microorganism and $15 \mathrm{ml}$ nutrient agar. Similarly, another plate is prepared using $0.1 \mathrm{ml}$ of $5 \%$ herbal extract, $0.1 \mathrm{ml}$ of $10^{3}$ dilution liquid containing microorganism and $15 \mathrm{ml}$ nutrient agar. Two more plates were prepared consisting of above composition excluding $0.1 \mathrm{ml}$ of $5 \%$ herbal extract. After the agar gets solidified, the plates were placed in incubator (at $38^{0} \mathrm{C}$ ) for 48 hours. After 48 hours, plate count was performed to determine the antimicrobial activities of Herbal extract.

\section{Results and Discussion}

Deviation from standard data during experiments may be due to collection of sample from different localities. Though the samples have been collected from same vendor but the result and observation we got is different sometime. In that case the average is taken as reading.

\section{Measurement of moisture content}

The moisture content was measured by placing $3 \mathrm{~g}$ sample in hot air oven at $105^{\circ} \mathrm{C}$. The experimentally obtained data of moisture content is $5.6 \%, 13.33 \%, 9.767 \%, 11.67 \%$ for Adhatoda vasica, Centella asiatica, Nyctanthes arbor-tristis, Paederia foetida respectively. 


\section{Moisture Content}

\begin{tabular}{|l|c|c|}
\hline \multicolumn{1}{|c|}{ Sample } & Calculated moisture content (\%) & $\begin{array}{c}\text { Standard moisture content } \\
(\%)\end{array}$ \\
\hline Adhatoda vasica & 15.17 & $15.3 \pm 0.5$ \\
\hline Centella asiatica & 14.8 & $7.15-12.3$ \\
\hline Paederia foetida & 11.5 & 11.5 \\
\hline Nyctanthes arbor-tristis & 17.95 & 18.25 \\
\hline Ocimum tenuiflorum & 11.58 & 13 \\
\hline
\end{tabular}

\section{Ash Content}

\begin{tabular}{l|}
$\qquad$ Sample \\
\hline Adhatoda vasica \\
\hline Centella asiatica \\
\hline Paederia foetida \\
\hline Nyctanthes arbor-tristis \\
\hline Ocimum tenuiflorum \\
\hline
\end{tabular}

\begin{tabular}{|c|c|}
\hline $\begin{array}{c}\text { Calculated ash content } \\
(\%)\end{array}$ & $\begin{array}{c}\text { Standard ash content } \\
(\%)\end{array}$ \\
\hline 5.6 & $5.2 \pm 1.23$ \\
\hline 11.67 & 8.06 to11.6 \\
\hline 9.767 & 10 \\
\hline 13.33 & 13.98 \\
\hline 15 & 14.74 \\
\hline
\end{tabular}

Total Phenolic Content measured at 765 nm

\begin{tabular}{|l|}
\multicolumn{1}{|c|}{ Sample } \\
\hline Adhatoda vasica \\
\hline Centella asitica \\
\hline Paederia foetida \\
\hline Nyctanthes arbor-tristis \\
\hline Ocimum tenuiflorum \\
\hline
\end{tabular}

Total phenolic content
$63.95 \pm 2.1$ to $92.4 \pm 0.14 \mathrm{mg} \mathrm{GAE} / \mathrm{g}$ of extracts
$3.23-11.7 \mathrm{~g} \mathrm{GAE} / 100 \mathrm{~g}$ of extract
$35.67 \mathrm{mg} \mathrm{GAE} / \mathrm{g}$ of the extract
$304.5 \mathrm{mg} \mathrm{GAE} / \mathrm{g}$ of extract
$279.05 \pm 0.73 \mathrm{mg} \mathrm{GAE} / \mathrm{g}$ of extract

Name of the Medicinal Herb

\section{Adhatoda vasica}

Centella asiatica

Nytanthes arbor-tristis

Paederia foetida

Ocimum tenuiflorum

\section{Microorganism}

\section{Escherichia coli, Bacillus subtilis}

Staphylococcus aureus, Escherichia coli, Klebsiella pneumoniae

Escherichia coli, Klebsiella pneumoniae, Staphylococcus aureus.

Staphylococcus aureus, Escherichia coli

Escherichia coli, Staphylococcus aureus

\section{SPC count}

SPC for 5\% Adhatoda vasica leaves extract
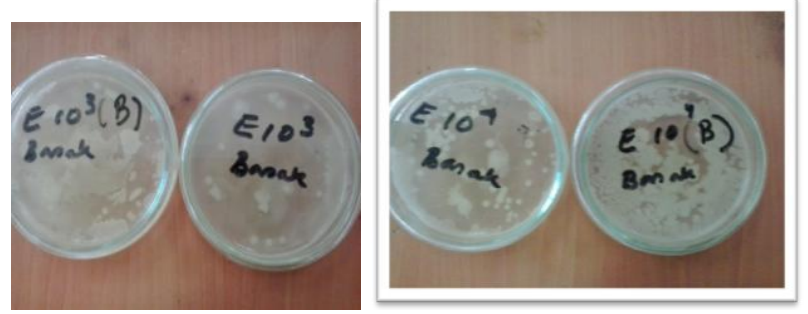

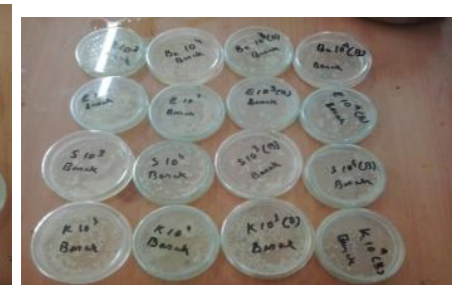



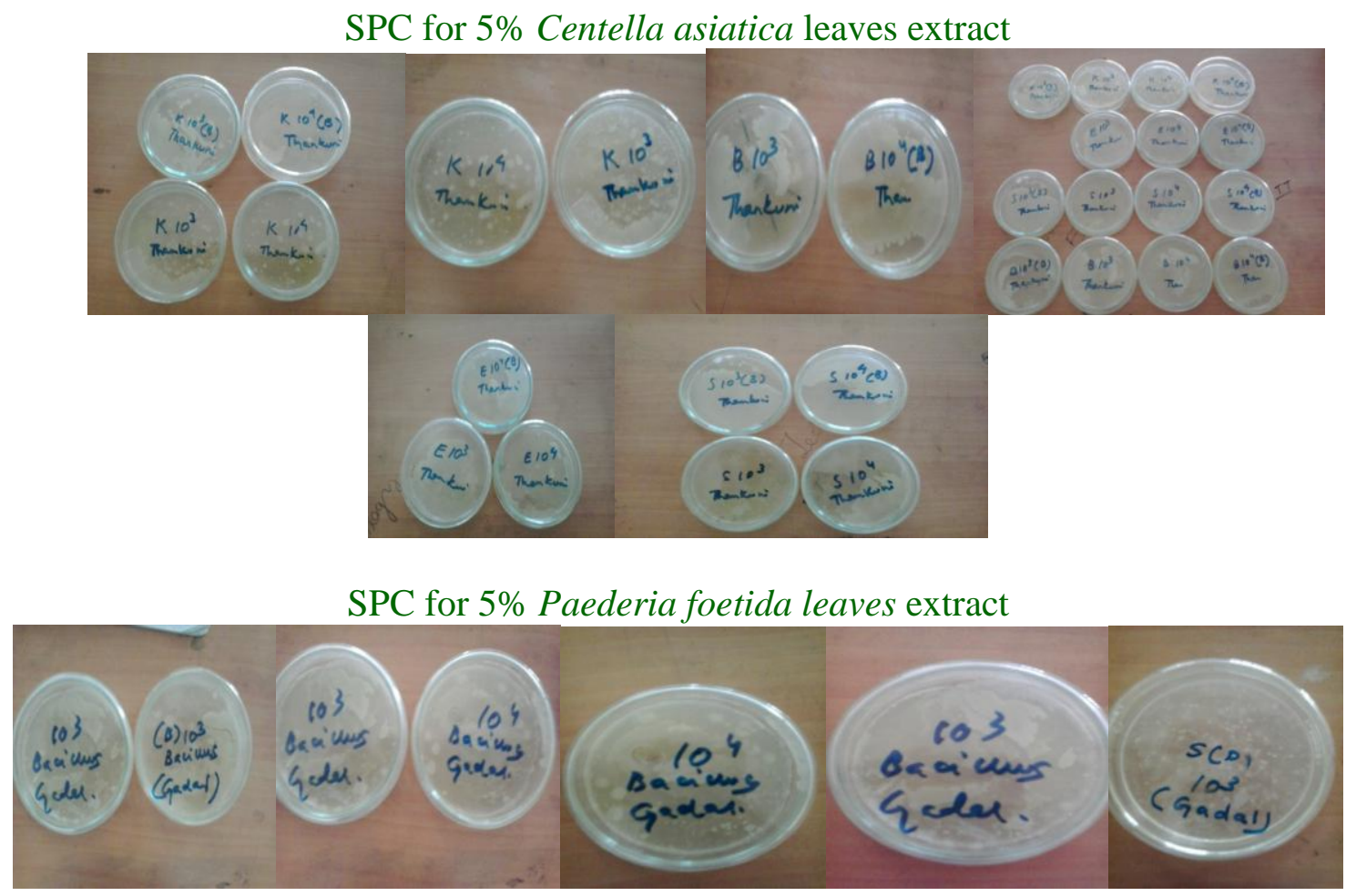

SPC for 5\% Ocimum tenuiflorum leaves extract:

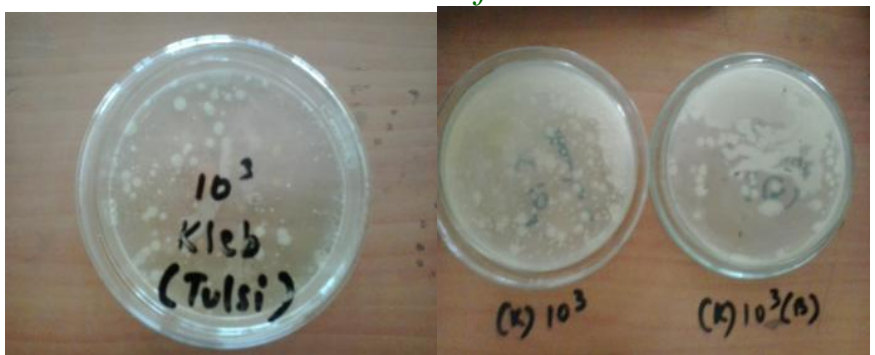

SPC $(\mathrm{cfu} / \mathrm{ml})=($ Number of colony $) /($ dilution factor* amount of diluents $)$

\section{Measurement of ash content}

The ash content measurement was measured by placing $3 \mathrm{~g}$ sample in muffled furnace at $460^{\circ} \mathrm{C}$ for 3 hour. The experimental result obtained was $15.17 \%, 14.8 \%, 19.2 \%, 11.5 \%$ for Adhatoda vasica, Nyctanthes arbor-tristis, Paederia foetida, Centella asiatica respectively.

\section{Measurement of phenolic content}

The amount of total phenol was determined with the Folin-Ciocalteu reagent. Gallic acid was used as a standard compound and the total phenols were expressed as $\mathrm{mg} / \mathrm{g}$ gallic acid equivalent using the standard curve equation. Where ordinate is absorbance at 765 $\mathrm{nm}$ and abscissa is total phenolic content in the different extracts of Adhatoda vasica, Centella asiatica, Paederia foetida, and Nyctanthes arbor-tristis expressed in $\mathrm{mg} / \mathrm{g}$. Phenolic compounds are a class of antioxidant agents which acts as free radical terminators. The total phenol varied from $63.95 \pm 2.1$ to $92.4 \pm 0.14 \mathrm{mg} / \mathrm{g}, \quad 3.23-11.7 \mathrm{~g} / 100 \mathrm{gm}$ of extract, $35.67 \mathrm{mg}$ of GAE/g of the extract, $304.5+1.70 \mathrm{mg}$ GAE/g of extract in Adhatoda vasica, Centella asitica, Paederia foetida, Nyctanthes arbor tristis respectively. 


\section{Measurement of anti-microbial activity}

The antimicrobial activity was determined using Standard Plate Count Method. The extracts from the leaves and stems of Adhatoda vasica, Centella asiatica, Paederia foetida, Ocimum tenuiflorum were tested against some pathogenic organisms like Escherichia coli, Bacillus subtilis, Klebsiella pneumoniae and Staphylococcus aureus. The extracts exhibited antibacterial activity against tested organisms. The results obtained indicated that the leaves of the plant could be a potential source of treatment of disease against the test organism. These findings support the traditional knowledge of local users about their selection of plant samples as antimicrobial agents and the use of these plants for antibacterial activity. The results of the present study also support the medicinal usage of the studied plant and suggest that the plant extracts possess compounds with antibacterial properties that can be used as antimicrobial agents in new drugs for the therapy of infectious diseases.

Medicinal plants have complex anti-oxidative machinery that protects them against oxidative damage. Sources of these natural antioxidants are primarily phenolics and flavonoids that may occur in all products and parts of a plant. On the basis of the data obtained in the present study, it is concluded that the ethyl acetate fractions obtained from the leaves of Nyctanthes arbor-tristis, Adhatoda vasica, Centella asiatica, Paederia foetida contain certain components which contribute to their antioxidant activities. The presence of polyphenolic compounds in the fraction might be the major contributor of antioxidant capacity and therefore the study provides preliminary pharmacological support for utilizing them in therapeutic usage.

\section{References}

Chopra, R.N., Nayer, S.L., Chopra, I.C. Ed. 1992 Glossary of Indian Medicinal Plants, $3^{\text {rd }}$ Ed., Council of Scientific and Industrial Research, New Delhi : 7246.

Ghani, A. 2003 Medicinal Plants of Bangladesh with chemical constituents and uses. $2^{\text {nd }}$ Ed., Asiatic Society of Bangladesh, Dhaka.

Parab, L.S., Satam, N.K., Bhagwat, A.M., Bhoir, S.I. 2013 Supercritical Fluid Extraction and Evaluation of Antioxidant Activity of Flavonoids from Nyctanthes arbor-tristis $L$ leaves Int. J. Pharm. Sci. 5, 256-261.

Tan, P.W., Tan, C.P., Ho, C.W. 2011 Antioxidant Properties: Effects of Solidto- Solvent Ratio on Antioxidant Compounds and Capacities of Pegaga (Centella asiatica). Int. Food Res. Journal, 18, 553-558.

\section{How to cite this article:}

Anju Paul, Amit Kumar Barman, Pradip Kumar Roy and Subhajit Ray. 2018. A Study on Antimicrobial Properties and Medicinal Value of Adhatoda vasica, Centella asiatica, Paederia foetida, Nyctanthes arbor-tristis, Ocimum tenuiflorum. Int.J.Curr.Microbiol.App.Sci. 7(05): 1406-1413. doi: https://doi.org/10.20546/ijcmas.2018.705.167 